\title{
Neuropsychological profiles of patients with obsessive-compulsive disorder: early onset versus late onset
}

\author{
SEON HEE HWANG, ${ }^{1,2}$ JUN SOO KWON, ${ }^{1,3,4}$ YONG-WOOK SHIN, ${ }^{1,2}$ KYUNG JIN LEE, ${ }^{4}$ \\ YOUNG YOUN KIM, ${ }^{1,4}$ AND MYUNG-SUN KIM ${ }^{2}$ \\ ${ }^{1}$ Clinical Research Center, Seoul National University Hospital, Seoul, South Korea \\ ${ }^{2}$ Department of Psychology, Sungshin Women's University, Seoul, Korea \\ ${ }^{3}$ Department of Psychiatry, Seoul National University College of Medicine, Seoul, Korea \\ ${ }^{4}$ BK21 Life Sciences \& Neuroscience Institute, SNU-MRC, Seoul, Korea
}

(Received January 11, 2006; Final Revision August 15, 2006; Accepted August 16, 2006)

\begin{abstract}
In this study, we assess the neuropsychological profiles of both early and late symptom-onset obsessive-compulsive disorder (OCD) patients. The early and late-onset OCD patients are compared to the control group with a series of neuropsychological measurements. The late-onset OCD patients exhibited impaired performance on the immediate and the delayed recall conditions of the Rey-Osterrieth Complex Figure Test (RCFT) and the letter and category fluency of the Controlled Oral Word Association Test (COWA), compared to the normal controls and the early-onset OCD patients. The controls and early-onset OCD patients did not differ on any of the neuropsychological measurements taken in this study. These results suggest that different neurophysiological mechanisms are in play in early and late-onset OCD patients, and age of onset can serve as a potential marker for the subtyping of OCD.

(JINS, 2007, 13, 30-37.)
\end{abstract}

Keywords: Obsessive-compulsive disorder (OCD), Subtype, Age of onset, Neuropsychological functions, Early-onset OCD, Late-onset OCD

\section{INTRODUCTION}

Obsessive-compulsive disorder (OCD) is characterized by obsession and compulsion severe enough to interfere with a person's ability to function on a daily basis (American Psychiatric Association, 1994). Recently, a growing body of evidence, in particular the results of neuroimaging studies, appears to suggest that OCD is a brain disorder involving neural loops that connect the prefrontal area and the basal ganglia (Mataix-Cols et al., 1999; Rauch, 2000). Brain imaging techniques, including computerized tomography (CT) and magnetic resonance imaging (MRI), have revealed morphological changes in the basal ganglia or frontal lobe of OCD patients (Grachev et al., 1998; Hoehn-Saric \& Green-

Correspondence and reprint requests to: Dr. Jun Soo Kwon, Professor, Department of Psychiatry, Seoul National University College of Medicine, 28 Yongon-dong, Chongno-gu, Seoul, Korea 110-744. E-mail: kwonjs@plaza.snu.ac.kr berg, 1997; Kim et al., 2001; Szeszko et al., 1999). Positron emission tomography (PET) and functional magnetic resonance imaging (fMRI) studies have also revealed abnormal activation in the striatum, orbitofrontal cortex, thalamus, and cingulate gyrus during the resting state (Baxter et al., 1992; Perani et al., 1995), as well as symptom provocation (Rauch et al., 1996; Shin et al., 2006) and cognitive activation (Pujol et al., 1999; Rauch et al., 1997).

Unlike brain imaging studies, neuropsychological studies have shown impairments in various cognitive domains in OCD patients. For example, some studies have reported deficits in attentional set-shifting ability and response inhibition in OCD patients (Head et al., 1989; Martinot et al., 1990; Veale et al., 1996). Others have found deficits in the visual memory and visuospatial ability (Christensen et al., 1992; Savage et al., 1999; Shin et al., 2004a, 2004b; Tallis et al., 1999). In addition, motor slowness or impairment of spatial working memory in OCD patients has been reported (Mataix-Cols et al., 1999; Purcell et al., 1998). 
These inconsistent neuropsychological findings may be attributable to heterogeneity with regard to certain aspects of patient selection, including clinical status of the subjects, or obsessive-compulsive symptoms evidenced (Schmidtke et al., 1998). Because these inconsistent findings render it fairly difficult to link the cognitive impairments associated with OCD patients to a specific underlying neuropathology, several attempts have been made to classify OCD patients, based on their symptoms (Arts et al., 1993), clinical course (Ravizza et al., 1997), or genetic information (Pauls, 1992).

Attempts have also been made to subtype OCD based on the age of symptom onset. Some studies have reported that early and late-onset OCD patients differ with regard to therapeutic outcomes and clinical characteristics. For example, Rosario-Campos et al. (2001) reported that adult earlyonset OCD patients tend to exhibit less favorable therapeutic responses to selective serotonin reuptake inhibitors (SSRIs) than do late-onset OCD patients. In addition, Jaisoorya et al. (2003) observed a higher incidence of comorbid tic disorders in early-onset OCD patients than in lateonset OCD patients. Furthermore, brain-imaging studies have indicated differences between early and late-onset OCD patients in terms of brain structure and function. For example, volume reduction and/or hypermetabolism in the striatum have been consistently observed in early-onset OCD patients (Gilbert et al., 2000; Kim, 2003), but these structural and/or functional abnormalities have not been consistently observed in the striatum of late-onset OCD patients (Aylward et al., 1996). Contrary to the results of clinical and neuroimaging studies, Roth et al. (2005) reported that the late onset OCD patients obtained poorer scores on measures of executive function and auditory attention than the early onset OCD patients.

The classification of OCD into subtypes with distinct characteristics would clearly be valuable with regard to our current understanding of the pathophysiology of OCD, and might also prove useful in the development of effective treatment strategies. In this study, we have attempted to compare the neuropsychological profiles of early and lateonset OCD patients, in order to determine whether the age of symptom-onset might serve as a potential marker for the subtyping of OCD.

\section{METHODS}

\section{Subjects}

Twenty-four early-onset OCD patients (onset age $\leq 17$ ), and 24 late-onset patients (onset age $\geq 21$ ) were recruited from the OCD outpatient clinic of the Seoul National University Hospital. All of the study patients met the criteria of the Diagnostic and Statistical Manual of Mental Disorders-IV (DSM-IV) for a diagnosis of OCD (American Psychiatric Association, 1994), based on the Structured Clinical Interview for the DSM-IV (SCID: First et al., 1996). Because there is no agreement regarding the age that defines the early and late-onset OCD at present (Hemmings et al., 2004; Rosario-Campos et al., 2001), we have chosen the early and late-onset OCD as having onset of symptoms at age 17 or earlier and at age 21 or later, respectively, based on a bimodal distribution of onset age, having two peaks separating each other with cutoff value of $<17$ for early onset and $>21$ for late onset OCD. All patients with histories of head injury, medical/neurological disorders, or alcohol and drug abuse were excluded from this study. However, the presence of any comorbid Axis I diagnosis did not necessarily constitute an exclusion criterion, if OCD was the primary diagnosis. Among 48 OCD patients, 1 had been diagnosed with dysthymia and 1 with social phobia. Also, one patient had been diagnosed with anorexia nervosa, and one with ADHD. The information was collected regarding age of symptomonset, at which the patients began to exhibit obsession or compulsion.

Twenty-four normal controls were recruited by advertising within the hospital and community colleges. These controls were matched to the patient groups by age, gender, years of education, and IQ. IQ was estimated by the Korean version of the Wechsler Adult Intelligence Scale (K-WAIS; Yum et al., 1992). Each of the three groups (early-onset OCD, late-onset OCD and normal controls) consisted of 12 men and 12 women. The research was completed in accordance with the Helsinki Declaration. This study was approved by the institutional review board at Seoul National University Hospital, and written informed consent was obtained from each participant. The controls were paid for participation in the study.

\section{Neuropsychological Measurements}

The following neuropsychological tests were administered during a single session, which lasted approximately 1 hour and 30 minutes. The Rey-Osterrieth Complex Figure Test (RCFT) was administered in order to evaluate nonverbal memory and visuospatial construction ability (Lezak, 1995). The administration of this test involves three conditions such as a copy, an immediate recall (3 minutes after copy condition) and a 30-minute delayed recall condition. The accuracy with regard to each condition was scored based on the system established by Meyers and Meyers (1995).

The Controlled Oral Word Association Test (COWA) was administered, in order to evaluate the patients' verbal fluency. The total number of responses for the letter and category was scored separately.

In order to measure a field of related abilities, including abstract concepts, problem solving, and shifting mental sets, the Wisconsin Card Sorting Test (WCST) was administered. The total number of correct responses, errors, perseverative responses, perseverative errors, and categories achieved were scored based on the scoring system established by Heaton (1981).

The Trail Making Test (TMT), part A and B, was administered. TMT is considered particularly effective for the evaluation of visual search ability (Reitan \& Wolfson, 1985), 
set-shifting ability, and controlled attention (Lezak, 1995). This test is scored according to response time and total number of errors. In order to estimate IQ, we administered the vocabulary, arithmetic, block design, picture arrangement, and digit span, which are subtests of the K-WAIS (Silverstein, 1989).

\section{Clinical Measurements}

The severity of OCD symptoms was evaluated by the YaleBrown Obsessive-Compulsive Scale (Y-BOCS; Goodman et al., 1989). Depression and anxiety severity were also assessed, using the Beck Depression Inventory (BDI; Beck et al., 1961) and the Beck Anxiety Inventory (BAI; Beck et al., 1988).

\section{Statistical Analysis}

Analysis of variance (ANOVA) was used to compare the demographic and clinical characteristics of the three groups (early-onset OCD vs. late-onset OCD vs. control). Group differences on the neuropsychological test scores were evaluated with ANOVA, and significant ANOVAs were followed by post hoc analyses using Fisher's least significant difference (LSD) test. Statistical significance was set at $p<.05$, and all of these analyses were conducted using the SPSS 11.0 software.

\section{RESULTS}

\section{Demographic and Clinical Data}

As shown in Table 1, the three groups exhibited no differences with regard to any of the demographic features, including age, gender, years of education, and IQ. The early- and late-onset OCD groups, however, showed significantly higher scores on the BDI, $[F(2,69)=17.11, p<.001]$, and the BAI, $[F(2,69)=19.28, p<.001]$, than did the control group. No significant differences were observed between the two OCD groups with regard to any of the clinical measurements, with the notable exceptions of age of onset, $t(46)=-15.841, p<.001$, and duration of illness $t(46)=$ 9.856, $p<.001$, which occurred significantly earlier and persisted longer in the early-onset OCD patients than in the late-onset patients.

\section{Neuropsychological Measures}

The performances of the three groups on the neuropsychological tests are summarized in Table 2. The three groups significantly differed with respect to the performances on the RCFT and COWA. With regard to the accuracy of the RCFT, the group effect was observed on the immediate recall condition, $[F(2,69)=8.590, p<.001]$, and the delayed recall condition, $[F(2,69)=10.445, p<.001]$. The lateonset OCD group performed worse on immediate recall condition than did the control group $(p<.001)$. No differ-

Table 1. Demographic and clinical data in the subjects

\begin{tabular}{|c|c|c|c|}
\hline & $\begin{array}{l}\text { Early onset OCD } \\
\qquad(n=24)\end{array}$ & $\begin{array}{l}\text { Late onset OCD } \\
\qquad(n=24)\end{array}$ & $\begin{array}{l}\text { Control } \\
(n=24)\end{array}$ \\
\hline & $\begin{array}{l}\text { Mean (SD) } \\
\quad \text { (range) }\end{array}$ & $\begin{array}{l}\text { Mean }(\mathrm{SD}) \\
\quad \text { (range) }\end{array}$ & $\begin{array}{l}\text { Mean }(\mathrm{SD}) \\
\quad(\text { range })\end{array}$ \\
\hline Age ( yrs.) & $27.54 \quad(3.72)$ & $29.50 \quad(3.05)$ & $27.92(4.73)$ \\
\hline Female/Male & $12 / 12$ & $12 / 12$ & $12 / 12$ \\
\hline Years of school & $15.17 \quad(1.55)$ & $15.08 \quad(1.98)$ & $15.58(1.47)$ \\
\hline Estimated IQ & $110 \quad(9.76)$ & $104.67(11.37)$ & $109.04(7.76)$ \\
\hline Age of onset & 14.58 (1.74) & $26.17(3.13)^{* * *}$ & - \\
\hline Duration of illness (yrs.) & $12.71 \quad(4.02)$ & $3.29(2.40)^{* * *}$ & - \\
\hline \multicolumn{4}{|l|}{ Y-BOCS } \\
\hline obsession & 11.89 (4.99) & $12.30 \quad(4.04)$ & - \\
\hline compulsion & $10.26 \quad(5.41)$ & $10.52 \quad(5.63)$ & - \\
\hline Total & $22.16 \quad(7.24)$ & $23.38 \quad(8.33)$ & - \\
\hline (range) & $(16-31)$ & $(17-35)$ & - \\
\hline $\mathrm{BDI}$ & $\begin{array}{c}19.04(9.25)^{* * * a} \\
(3-39)\end{array}$ & $\begin{array}{c}18.62(8.43)^{* * * a} \\
(0-59)\end{array}$ & $\begin{array}{l}6.83(6.75) \\
(0-19)\end{array}$ \\
\hline BAI & $\begin{array}{c}22.79(11.85)^{* * * a} \\
(2-38)\end{array}$ & $\begin{array}{c}16.63(7.41)^{* * * a} \\
(2-34)\end{array}$ & $\begin{array}{l}6.38(7.39) \\
(0-25)\end{array}$ \\
\hline
\end{tabular}

Note. Y-BOCS $=$ Yale-Brown Obsessive-Compulsive Scale, BDI = Beck Depression Inventory, $\mathrm{BAI}=$ Beck Anxiety Inventory. ${ }^{\mathrm{a}}$ Early onset OCD, Late onset OCD $>$ Control. $* * * p<.001$. 
Table 2. MANOVA as with BDI, BAI score a covariate comparing early onset OCD, late onset OCD and control groups on neuropsychological performance

\begin{tabular}{|c|c|c|c|}
\hline & $\begin{array}{l}\text { Early onset OCD } \\
\qquad(n=24)\end{array}$ & $\begin{array}{l}\text { Late onset OCD } \\
\qquad(n=24)\end{array}$ & $\begin{array}{l}\text { Control } \\
(n=24)\end{array}$ \\
\hline & Mean (SD) & Mean (SD) & Mean (SD) \\
\hline \multicolumn{4}{|l|}{ RCFT } \\
\hline \multicolumn{4}{|l|}{ Accuracy } \\
\hline Copy & $31.98 \quad(2.85)$ & $34.77(14.18)$ & $32.25 \quad(2.91)$ \\
\hline Immediate recall & $18.21 \quad(6.62)$ & $14.38(6.29)^{* * * a}$ & $21.38 \quad(4.43)$ \\
\hline Delayed recall & $18.50 \quad(6.23)$ & $13.78(6.09)^{* * * a,{ }^{* *} \mathrm{~b}}$ & $21.38 \quad(4.43)$ \\
\hline \multicolumn{4}{|l|}{ COWA } \\
\hline \multicolumn{4}{|l|}{ No. of responses } \\
\hline Letter & $38.50(10.05)$ & $28.88(8.68)^{* * * a,{ }^{* *} \mathrm{~b}}$ & $39.25 \quad(7.28)$ \\
\hline Category & $38.92(7.96)$ & $32.54(6.98)^{* * a, * b}$ & $40.67 \quad(9.30)$ \\
\hline \multicolumn{4}{|l|}{ TMT } \\
\hline \multicolumn{4}{|l|}{ Response time } \\
\hline Part A & $39.33(16.37)$ & $40.88(12.26)$ & $31.96 \quad(7.90)$ \\
\hline Part B & $107.71(98.05)$ & $83.88(33.85)$ & $75.17(28.25)$ \\
\hline \multicolumn{4}{|l|}{ WCST } \\
\hline \multicolumn{4}{|l|}{ No. of responses } \\
\hline Correct & $66.13(14.63)$ & $67.88(15.64)$ & $72.96 \quad(8.58)$ \\
\hline Perseverative & $16.83(25.02)$ & $16.50(15.93)$ & $9.63 \quad(6.42)$ \\
\hline Nonperseverative Error & $13.67(14.06)$ & $15.42(13.53)$ & $10.79 \quad(8.51)$ \\
\hline Categories & $4.83 \quad(2.22)$ & $5.08 \quad(1.93)$ & $5.58 \quad(1.05)$ \\
\hline \multicolumn{4}{|l|}{ K-WAIS } \\
\hline Vocabulary & $13.25 \quad(1.82)$ & $11.25(1.51)$ & $12.42 \quad(1.77)$ \\
\hline Digit span & $12.50 \quad(2.23)$ & $11.25 \quad(1.51)$ & $12.42 \quad(1.77)$ \\
\hline Picture arrangement & $10.75 \quad(1.92)$ & $10.75 \quad(1.73)$ & $11.38 \quad(1.86)$ \\
\hline Block design & 11.88 (2.33) & 10.67 (1.97) & 12.04 (1.94) \\
\hline Arithmetic & $12.17 \quad(2.35)$ & 11.38 (3.19) & $12.00 \quad(2.64)$ \\
\hline
\end{tabular}

Note . RCFT $=$ Rey-Osterrieth Complex Figure Test, $\mathrm{COWA}=$ Controlled Oral Word Association, $\mathrm{TMT}=$ Trail Making Test, WCST $=$ Wisconsin Card Sorting Test, K-WAIS $=$ Korean-Wechsler Adult Intelligence Scale.

${ }^{a}$ Late onset $\mathrm{OCD}<$ Control; ${ }^{\mathrm{b}}$ Late onset OCD $<$ Early onset OCD.

$* p<.05, * * p<.01, * * * p<.001$.

ence, however, was apparent between the early-onset OCD group and the control group, or between the early-onset OCD group and the late-onset OCD group. The late-onset OCD patients also exhibited poor performances on the delayed recall condition as compared to both the normal controls $(p<.001)$ and the early-onset OCD patients $(p<$ $.01)$. However, we observed no significant differences between the early-onset OCD group and the control group with regard to the immediate and delayed recall conditions of RCFT.

The group effect was also observed on letter, $[F(2,69)=$ $10.504, p<.001]$, and category of COWA, $[F(2,69)=$ $6.631, p<.01]$. For letter, the late-onset OCD group showed significantly fewer responses than did the control group $(p<.001)$ and the early-onset OCD group $(p<.01)$, whereas no significant differences could be observed between the early-onset OCD group and the control group. In terms of category, the late-onset OCD group showed significantly fewer responses than did the control group $(p<.01)$ and early-onset OCD group $(p<.05)$. However, the control and early-onset OCD groups did not differ.
No significant group effect was found on the performances of WCST and TMT. The observed group differences on the RCFT and COWA remained significant even after controlling for depression and anxiety using analysis of covariance.

\section{DISCUSSION}

In this study, we compared neuropsychological profiles of early and late-onset OCD patients, in order to determine whether the age of symptom-onset could serve as a marker for OCD subtype. The late-onset OCD patients showed poor performance on the immediate and delayed recall conditions of RCFT and COWA, as compared with the normal controls and the early-onset OCD patients. The controls and the early-onset OCD patients exhibited no differences on any of our neuropsychological measurements. Our results indicated that OCD patients exhibited different neuropsychological functions, depending on age of onset. Recently, Roth et al. (2005) investigated whether patients with early and late onset OCD differ with respect to neuropsycholog- 
ical functioning. Results revealed that the late onset OCD obtained poor score on measurement of executive function and auditory attention than early onset group. They suggested that early and late onset OCD may be the results of at least partially differing neurobiological mechanisms. These findings are also compatible with the results of this research.

The RCFT has been used extensively as a measurement of visuospatial constructive ability and visuospatial memory (Lezak, 1995). The precise cognitive operations required for adequate RCFT performance include visual perception, visuospatial organization, motor functioning and, on the recall conditions, memory (Chervinsky et al., 1992). Chiulli et al. (1995) have suggested that conditions of the copy, immediate recall, and delayed recall provide different information. They have insisted that, whereas the copy condition reflects perceptual, visuospatial, and organizational skill, the immediate recall reflects the amount of information encoded, and the delayed recall condition reflects the amount of information stored and retrieved from the memory.

In this study, late-onset OCD patients exhibited poor performance on immediate and delayed recall, suggesting that the late-onset OCD patients are impaired, not only with regard to the encoding of information but also in terms of their ability to store and retrieve that information. Previous studies, which employed the qualitative analysis of RCFT suggest that the impaired performance on immediate and delayed recalls in OCD patients appear to reflect the impairment of encoding, which seems to result from a disorganized piecemeal approach to copying of the figure (Deckersbach et al., 2000; Savage et al., 1999). For example, Savage et al. (1999) demonstrated, by multiple regression analysis, that poor performance on immediate recall was significantly mediated by copy organizational strategies. Deckersbach et al. (2000) also claimed that organization during the copy trial constitutes a strong predictor for subsequent immediate and delayed recall performances, because the organizational process of memory is crucial for the efficient encoding and retrieval of information. Therefore, the observed impaired performance on immediate and delayed recalls in the late-onset OCD patients possibly results from the impairment of encoding rather than the impairment of information storage or retrieval. Future study employing the qualitative analysis of RCFT would provide valuable information regarding whether the poor performance on immediate and delayed recalls reflect the impairment of encoding or impairment of information storage or retrieval in OCD patients.

The late-onset OCD patients differed from the controls and early-onset OCD patients with regard to their performance on the letter and category tests of COWA. The lateonset OCD patients generated fewer words than did the controls and early-onset OCD patients. Previous neuropsychological studies have yielded inconsistent results with regard to COWA. Some studies have reported significant differences between OCD patients and controls on COWA letter and/or category test (Christensen et al., 1992; Schmidtke et al., 1998), but others have detected no differ- ences between the two groups (Martin et al., 1993). It has been suggested that COWA reflects the initiation of rapid and spontaneous thought and action, as well as self-guided, flexible behavior (Devinsky et al., 1995). In addition, several studies have reported that COWA is sensitive to prefrontal dysfunction, and in particular, to dysfunctions of the medial and orbitofrontal areas (Crowe, 1992; Miceli et al., 1981). For example, Pujol et al. (1999) observed abnormal activation occurring in the frontal area when OCD patients took the COWA test, and the abnormal activation was associated with the severity of OCD symptoms. In addition, activation of the bilateral frontal and temporal lobes has been observed during the performance of the COWA test by normal subjects (Cantor-Graae et al., 1993; Parks et al., 1988). Therefore, poor COWA performance by the lateonset OCD patients would suggest that these patients suffer from a reduced initiation of spontaneous thought/action and flexible behavior, both of which may be mediated by the frontal-striatal system.

There was little difference between the OCD and control groups in terms of the WCST performance, which is widely used to measure the executive function. Previous studies reported inconsistent findings in terms of the WCST performance in OCD patients. For example, Head et al. (1989) reported a significant difference between OCD patients and controls, whereas Abbruzzese et al. (1995) and Roth et al. (2005) found no difference. Christensen et al. (1992) reported evidence for executive dysfunction becoming weaker in some studies where the educational level and/or verbal IQ of the subjects were well controlled. Therefore, the similarity in the OCD and control groups in terms of the WCST performance is most likely caused by the subjects' controlled educational level and/or IQ used in this study.

The early-onset OCD patients have been reported to exhibit stronger family loading, worse medication responses, and a higher frequency of comorbidity as compared to the late-onset OCD patients (Jaisoorya et al., 2003; Pauls, 1996; Rosario-Campos et al., 2001). All of these findings in earlyonset OCD patients provided the basis for the conjecture that early-onset patients would suffer from more severe neuropsychological dysfunction than would late-onset OCD patients. However, unexpectedly, the early-onset OCD patients exhibited no impairments in comparison to the normal controls, on any of the neuropsychological measurements taken. Even after the mood symptoms have been controlled, the late-onset OCD patients showed worse performance on the RCFT and COWA than did the early-onset patients. These results seem to reflect that the neuropsychological measurements taken in this study are not sensitive enough to the cognitive dysfunctions of the early-onset OCD.

In the light of the present findings, it certainly appears that there are different neurophysiological mechanisms underlying the conditions of the early and late-onset OCD patients, and age of onset can serve as a potential marker for the subtypying of OCD. These results are consistent with those of imaging studies. Previous studies have consistently reported that early-onset OCD patients exhibit 
reductions of volume and/or hypermetabolism in the striatum (Gilbert et al., 2000; Kim, 2003), but these structural and/or functional abnormalities of the striatum have not been consistently observed in late-onset OCD patients (Aylward et al., 1996). In addition, different patterns of brain activation were observed in OCD patients depending on the age of symptom onset. For example, Busatto et al. (2001) have reported that early-onset OCD patients showed abnormal resting blood flow in the anterior cingulate gyrus, orbitofrontal gyrus, and cerebellum; whereas late-onset patients showed predominant abnormalities in orbitofrontal cortex and precuneus. These findings suggest that there are different neurobiological mechanisms underlying early and lateonset OCD. However, future studies, employing both structural-functional brain imaging techniques and neuropsychological tests, should be conducted in order to clarify whether different neurophysiological mechanisms are, indeed responsible for early- and late-onset OCD. It would also be desirable to investigate a subclinical OCD group or a group of patients with OCD spectrum disorders, because neuropsychological dysfunctions, including impairment of visual memory and inabilities to manipulate visuospatial information, have also been observed in such patients (Braun et al., 1995; Mataix-Cols et al., 1999). However, because we employed somewhat arbitrarily cutoff defining the early and late-onset OCD and the retrospective report from patients or family members regarding age of symptom onset, caution should be exercised before accepting the generality of the findings.

In summary, the late-onset OCD patients evidenced poor performance on immediate and delayed recall conditions of the RCFT and COWA, as compared to the normal controls and early-onset OCD patients. The normal controls and earlyonset OCD patients were not found to differ with regard to any of the neuropsychological measurements taken in this study. The poor performance on RCFT and COWA by the late-onset OCD patients persisted even after mood symptoms were controlled. These results indicate that different neurophysiological mechanisms are responsible for earlyand late-onset OCD, and age of onset can serve as a potential marker for the subtyping of OCD.

\section{ACKNOWLEDGMENTS}

This research was supported by a grant (M103KV010007 4K2201 00710) from Brain Research Center of the 21st Century Frontier Research Program funded by the Ministry of Science and Technology of Republic of Korea. The manuscript is new and original and it has never been published either electronically or in print. All of the authors have no conflict of interest affecting this study.

\section{REFERENCES}

Abbruzzese, M., Ferri, S., \& Scarone, S. (1995). Wisconsin card sorting test performance in obsessive-compulsive disorder: No evidence for involvement of dorsolateral prefrontal cortex. Psychiatry Research, 58, 37-43.
American Psychiatric Association. (1994). Diagnostic and statistical manual of mental disorder. 4th ed. Washington: American Psychiatric Association.

Arts, W., Hoogduin, K., Schaap, C., \& de Haan, E. (1993). Do patients suffering from obsessions alone differ from other obsessive-compulsives? Behavior Research and Therapy, 31, 119-123.

Aylward, E.H., Harris, G.I., Hoehn-Saric, R., Barta, P.E., Machlin, S.R., \& Pearlson, G.D. (1996). Normal caudate nucleus in obsessive-compulsive disorder assessed by quantitative neuroimaging. Archives of General Psychiatry, 53, 577-584.

Baxter, L.R., Schwartz, J.M., Bergman, K.S., Szuba, M.P., Guze, B.H., \& Mazziotta, J.C. (1992). Caudate glucose metabolic rate changes with both drug and behavior therapy for obsessivecompulsive disorder. Archives of General Psychiatry, 49, 681-689.

Beck, A., Ward, C., Mendelson, M., Mock, J., \& Frbaugh, J. (1961). An inventory for measuring depression. Archives of General Psychiatry, 4, 561-591.

Beck, A., Epstein, N., Brown, G., \& Robert, A.S. (1988). An inventory for measuring clinical anxiety: Psychometric properties. Journal of Consult Clinical Psychology, 56, 893-897.

Braun, A., Randolph, C., Stoetter, B., Mohr, E., Cox, C., Vladar, K., Sexton, R., Carson, E., Herscovitch, P., \& Chase, T. (1995). The functional neuroanatomy of Tourette's syndrome: An FDGPET study II: Relationships between regional cerebral metabolism and associated behavioral and cognitive features of the illness. Neuropsychopharmacology, 13, 151-168.

Busatto, G.F., Buchpiguel, C.A., Zamignani, D.R., Garrido, G.E.J., Glabus, M.F., Rosario-Campos, M.C., Castro, C.C., Maia, A., Rocha, E.T., Mcguire, P.K., \& Miguel, E.C. (2001). Regional cerebral blood flow abnormalities in early-onset obsessivecompulsive disorder: An exploratory SPECT study. Journal of the American Academy of Child and Adolescent Psychiatry, 40, 347-354.

Cantor-Graae, E., Warkentin, S., Franzen, G., \& Risberg, J. (1993). Frontal lobe challenge: A comparison of activation procedures during rCBF measurement in normal subjects. Neuropsychiatry, Neuropsychology and Behavioral Neurology, 6, 83-92.

Chervinsky, A.B., Mitrushina, M., \& Satz, P. (1992). Comparison of four methods of scoring the Rey-Osterrieth Complex Figure Drawing Test on four age groups of normal elderly. Brain Dysfunction, 5, 267-287.

Chiulli, S.J., Haalaud, K.Y., LaRue, A., \& Garry, P.J. (1995). Impact of age on drawing the Rey-Osterrieth Figure. The Clinical Neuropsychologist, 9, 219-224.

Christensen, K.J., Kim, S.W., Dysken, M.W., \& Hoover, K.M. (1992). Neuropsychological performance in obsessivecompulsive disorder. Biological Psychiatry, 31, 4-18.

Crowe, S.F. (1992). Dissociation of two frontal lobe syndromes by a test of verbal fluency. Journal of Clinical and Experimental Neuropsychology, 14, 327-339.

Deckersbach, T., Savage, C.R., Henin, A., Mataix-Cols, D., Otto, M.W., Wilhelm, S., Rauch, S.L., Baer, L., \& Jenike, M.A. (2000). Reliability and validity of a scoring system for measuring organizational approach in the Complex Figure Test. Journal of Clinical and Experimental Neuropsychology, 22, 640-648.

Devinsky, O., Morrell, M.J., \& Vogt, B.A. (1995). Contributions of anterior cingulated cortex to behavior. Brain, 118, 279-306. 
First, M.B., Spitzer, R.L., Gibbon, M., \& Williams, J.B.W. (1996). Structured clinical interview for DSM-IV Axis I disorder. NY: New York State Psychiatric Institute.

Gilbert, A.R., Moore, G.J., Keshavan, M.S., Paulson, L.A., Narula, V., Mac Master, F.P., Stewart, C.M., \& Rosenberg, D.R. (2000). Decrease in thalamic volumes of pediatric patients with obsessive-compulsive disorder who are taking paroxetine. Archives of General Psychiatry, 57, 449-456.

Goodman, W., Price, L., Rasmussen, S., Mazure, C., Fleischmann, R.L., \& Hill, C.L. (1989). The Y-BOCS(1). development, use and reliability. Archives of General Psychiatry, 46, 1006-1011.

Grachev, I.D., Breiter, H.C., Rauch, S.L., Scott, L., Savage, C.R., Baer, L., Shera, D.M., Kennedy, D.N., Makris, N., Caviness, V.S., \& Jenike, M.A. (1998). Structural abnormalities of frontal neocortex in obsessive-compulsive disorder. Archives of General Psychiatry, 55, 181-182.

Head, D., Bolton, D., \& Hymas, N. (1989). Deficit in cognitive shifting ability in patients with obsessive-compulsive disorder. Biological Psychiatry, 25, 929-937.

Heaton, R.K. (1981). Wisconsin Card Sorting Test Manual. Odessa, FL: Psychological Assessment Cooperation Press.

Hemmings, S.M.J., Kinnear, C.J., Lochner, C., Niehaus, D.J.H., Knowles, J.A., Moolman-Smook, J.C., Corfield, V.A., \& Stein, D.J. (2004). Early- versus late-onset obsessive-compulsive disorder: Investigating genetic and clinical correlates. Psychiatry Research, 128, 175-182.

Hoehn-Saric, R., \& Barksdale, V.C. (1983). Impulsiveness in obsessive-compulsive patients. British Journal of Psychiatry, 143, 177-182.

Jaisoorya, T.S., Janardhan Reddy, Y.C., \& Srinath, S. (2003). The relationship of obsessive-compulsive disorder to putative spectrum disorders: Results from an India study. Comprehensive Psychiatry, 44, 317-323.

Kim, B.N. (2003). Child and adolescent onset obsessive-compulsive disorder. Korean Journal of Psychopharmacology, 14, 119-128.

Kim, J.J., Lee, M.C., Kim, J.S., Kim, I.Y., Kim, S.I., Han, M.H., Chang, K.H., \& Kwon, J.S. (2001). Grey matter abnormalities in obsessive-compulsive disorder: Statistical parametric mapping of segmented magnetic resonance images. British Journal of Psychiatry, 179, 330-334.

Lezak, M.D. (1995). Neuropsychological assessment, 3rd ed. New York: Oxford.

Martin, A., Pigott, J.A., Lalonde, F.M., Dalton, I., Dubbert, B., \& Murphy, D.L. (1993). Lack of evidence for Hungtington's disease-like cognitive function in obsessive-compulsive disorder. Biological Psychiatry, 33, 345-353.

Martinot, J.L., Allilaire, J.F., Mazoyer, B.M., Hantouche, E., Huret, J.D., Legaut-Demare, F., Deslauriers, A.G., Hardy, P., Pappata, S., \& Baron, J.C. (1990). Obsessive-compulsive disorder: A clinical, neuropsychological and positron emission tomography study. Acta Psychiatric Scandinavia, 82, 233-242.

Mataix-Cols, D., Junque, C., Sanchez-Turet, M., Vallezo, J., Verger, K., \& Barrios, M. (1999). Neuropsychological functioning in a subclinical obsessive-compulsive sample. Biological Psychiatry, 45, 898-904.

Meyers, J.E., \& Meyers, K.R. (1995). Rey Complex Figure Test and Recognition Trial. Lutz, FL: Psychological Assessment Resources, Inc.

Miceli, G., Caltagirone, C., Gainotti, G., Masullo, C., \& Sillveri, M.C. (1981). Neuropsychological correlates of localized cerebral lesions in nonaphasic brain-damaged patients. Journal of Clinical Neuropsychology, 3, 53-63.
Parks, R.W., Loewenstein, D.A., Dodrill, K.L., Barker, W.W., Yoshii, F., Chang, J.Y., Emran, A., Apicella, A., Sheramata, W.A., \& Duara, R. (1988). Cerebral metabolic effects of a verbal fluency test: A PET scan study. Journal of Clinical and Experimental Neuropsychology, 10, 565-575.

Pauls, D.L. (1992). The genetics of obsessive compulsive disorder and Gilles de la Tourette's syndrome. The Psychiatric Clinics of North America, 15, 759-766.

Pauls, D.L. (1996). Genetics of the Gilles de la Tourette's syndrome and obsessive compulsive disorder. European Neuropsychopharmacology, 6, S4.

Perani, D., Colombo, C., Bressi, S., Bonfanti, A., Grass, F., Scarone, S., Bellodi, L., Smeraldi, E., \& Fazio, F. (1995). [18F] FDG PET study in obsessive-compulsive disorder: A clinical/ metabolic correlation study after treatment. British Journal of Psychiatry, 166, 244-250.

Pujol, J., Torres, L., Deus, J., Cardoner, N., Pifarre, J., Capdevila, A., \& Vallejo, J. (1999). Functional magnetic resonance imaging study of frontal lobe activation during word generation in obsessive-compulsive disorder. Biological Psychiatry, 45, 891-897.

Purcell, R., Maruff, P., Kyrios, M., \& Pantelis, C. (1998). Cognitive deficits in obsessive-compulsive disorder on tests of frontalstriatal function. Biological Psychiatry, 43, 348-357.

Rauch, S.L., Kolk, B.A., Fisler, R.E., Alpert, N.M., Orr, S.P., Savage, C.R., Fischman, A.J., Jenike, M.A., \& Pitman, R.K.( 1996). A symptom provocation study of posttraumatic stress disorder using positron emission tomography and script-driven imagery. Archives of General Psychiatry, 53, 380-387.

Rauch, S.L., Savage, C.R., Alpert, N.M., Dougherty, D., Kendrick, A., \& Curran, T. (1997). Probing striatal function in obsessive-compulsive disorder: A PET study of implicit sequence learning. Journal of Neuropsychiatry and Clinical Neuroscience, 9, 568-573.

Rauch, S.L. (2000). Neuroimaging research and the neurobiology of obsessive-compulsive disorder: Where do we go from here? Biological Psychiatry, 47, 168-170.

Ravizza, L., Maina, G., \& Bogetto, F. (1997). Episodic and chronic obsessive-compulsive disorder. Depress Anxiety, 6, 154-158.

Reitan, R.M. \& Wolfson, D. (1985). The Halstead-Reitan neuropsychological test battery. Tucson, AZ: Neuropsychology Press.

Rosario-Campos, M.C., Leckman, J.F., Mercadante, M.T., Shavitt, R.G., Prado, H.S., Sada, P., Zamignani, D., \& Miguel, E.C. (2001). Adults with early-onset obsessive-compulsive disorder. American Journal of Psychiatry, 158, 1899-1903.

Roth, R.M., Milovan, D., Baribeau, J., \& O'Connor, K. (2005). Neuropsychological functioning in early- and late-onset obsessive-compulsive disorder. Journal of Neuropsychiatry and Clinical Neuroscience, 17, 208-213.

Savage, C.R., Baer, L., Keuthen, N.J., Brown, H.D., Rauch, S.L., \& Jenike, M.A. (1999). Organizational strategies mediate nonverbal memory impairment in obsessive-compulsive disorder. Biological Psychiatry, 45, 905-916.

Schmidtke, K., Schorb, A., Winkelmann, G., \& Hohagen, F. (1998). Cognitive frontal lobe dysfunction in obsessive-compulsive disorder. Biological Psychiatry, 43, 666-673.

Shin, M.S., Park, S.J., Kim, M.S., Lee, Y.H., Ha, T.H., \& Kwon, J.S. (2004a). Deficits of Organizational Strategy and Visual Memory in Obsessive-Compulsive Disorder. Neuropsychology, 18, 665-672.

Shin, Y.W., Ha, T.H., Kim, S.Y., \& Kwon, J.S. (2004b): Associa- 
tion between EEG alpha power and visuospatial function in obsessive-compulsive disorder. Psychiatry and Clinical Neuroscience, 58, 16-20.

Shin, Y.W., Kwon, J.S., Kim, J.J., Kang, D.H., Youn, T., Kang, K.W., Kang, E., Lee, D.S., \& Lee, M.C. (2006). Altered neural circuit for working memory before and after symptom provocation in patients with obsessive-compulsive disorder. Acta Psychiatrica Scandinavica, 113, 420-429.

Silverstein, A.B. (1989). Agreement between a short-form and the full scale as a function of the correlation between them. Journal of Clinical Psychology, 45, 929-931.

Szeszko, P.R., Robinson, D., Alvir, J., Ma, J., Bilder, R.M., Lencz, T., Ashtari, M., Wu, H., \& Bogerts, B. (1999). Orbital frontal and amygdala volume reductions in obsessive-compulsive disorder. Archives of General Psychiatry, 56, 913-919.

Tallis, F., Pratt, P., \& Jamani, N. (1999). Obsessive-compulsive disorder, checking and non-verbal memory: A neuropsychological investigation. Behaviour Research and Therapy, 37, 161-166.

Veale, D.M., Sahakian, B.J., Owen, A.M., \& Marks, I.M. (1996). Specific cognitive deficits in tests sensitive to frontal lobe dysfunction in obsessive-compulsive disorder. Psychological Medicine, 26, 1261-1269.

Yum, T.H., Park, Y.S., Oh, K.J., Kim, J.G., \& Lee, Y.H. (1992). The Manual of Korean-Wechsler Adult Intelligence Scale. Seoul: Korean Guidance Press. 